\title{
Influência dos parâmetros urbanísticos e da topografia na admissão da luz natural em edifícios residenciais
}

\author{
Urban parameters and terrain slope influence over the \\ daylight admission in residential buildings
}

\section{Cláudia Rocha Guidi \\ Karla Cristina de Freitas J orge Abrahão \\ Ana Carolina Oliveira Veloso \\ Roberta Vieira Gonçalves de Souza}

\section{Resumo}

$\mathbf{E}$

m Belo Horizonte, os parâmetros urbanísticos municipais associados às características topográficas da malha urbana da cidade levaram a crer que a quantidade de luz natural admitida nos ambientes residenciais, especialmente em andares inferiores, poderia ser bastante reduzida. A proposta deste trabalho foi então analisar a admissão de luz natural em edifício residencial inserido na malha urbana da cidade sob a influência de diferentes topografias. Para isso, foram investigadas a declividade do terreno e a localização vertical da unidade residencial em quatro orientações geográficas por meio dos critérios propostos no RTQ-R e na NBR 15575-1. Para atendimento da NBR 15575-1, as iluminâncias internas foram obtidas de acordo com as partes 2 e 3 da NBR 15215 e também por simulação computacional. Verificou-se que pelo método prescritivo da NBR 15575-1 todos os ambientes atenderam aos limites para desempenho mínimo. Já por simulação, de 6\% a 9\% dos valores não atenderam a esses limites. A diferenciação em relação à topografia e à localização vertical da unidade foi notada mais significativamente na avaliação feita de acordo com o RTQ-R. Os resultados obtidos neste caso indicaram que apenas 19\% dos ambientes situados no primeiro pavimento e $50 \%$ de todos os ambientes localizados na maior declividade atenderam aos requisitos para bonificação. Os resultados parecem indicar ainda que a legislação municipal deveria ser revisada nas situações de maiores declividades.

Palavras-chave: Iluminação natural. Simulação de luz natural. RTQ-R. NBR 15575-1. Legislação urbanística.

Cláudia Rocha Guidi Universidade Federal de Minas Gerais Belo Horizonte - MG - Brasil

Karla Cristina de Freitas J orge Abrahão Universidade Federal de Minas Gerais Belo Horizonte - MG - Brasil

Ana Carolina Oliveira Veloso Universidade Federal de Minas Gerais Belo Horizonte - MG - Brasil

Roberta Vieira Gonçalves de

Souza

Universidade Federal de Minas Gerais Belo Horizonte - MG - Brasil

Recebido em 23/11/17 Aceito em 03/03/18

\section{Abstract}

In Belo Horizonte, the municipal urban parameters associated to the topographic characteristics of the city's urban mesh led to the belief that the amount of daylighting allowed in residential environments, especially on lower floors, could be greatly reduced. The purpose of the present study was to evaluate the daylight admission in residential building in the city's urban mesh under the influence of several different topographic. The analysis addressed the slope, the vertical location of the unit in 4 geographic orientations. The evaluations were carried out according to RTQ-R and to NBR 15575-1 requirements using NBR 15215 parts 2 and 3 and computer simulations. Using the NBR 15575-1 method all illuminances were within the minimum values. Using computer simulation $6 \%$ to $9 \%$ of the values did not meet the minimum established values. The difference between the slope and the vertical location of the unit was noticed more significantly in the evaluation made according to the RTQ-R. The results showed that $19 \%$ of the first floor rooms and $50 \%$ of all rooms located in the worst slope meet the RTQ-R bonus requirements. It was indicated that the city urban legislation should be revised including the analysis of the worst terrain slopes.

Keywords: Daylighting. Daylighting simulation. NBR 15575-1. RTQ-R. Urban legislation.

GUIDI, C. R.; ABRAHÃO, K. C. de F. J .; VELOSO, A. C. O.; SOUZA, R. V. G. de. Influência dos parâmetros urbanísticos e 49 da topografia na admissão da luz natural em edifícios residenciais. Ambiente Construído, Porto Alegre, v. 18, n. 3, p. 49-66, jul./ set. 2018.

ISSN 1678-8621 Associação Nacional de Tecnologia do Ambiente Construído.

http:/ / dx. doi. org/ 10.1590/ s1678-86212018000300267 


\section{Introdução}

A iluminação natural é considerada como uma das melhores fontes de iluminação devido a suas propriedades de reprodução de cor, o que contribui para o conforto visual humano (ALRUBAIH et al., 2013). Ela é definida como a luz proveniente do sol de forma direta, luz difundida pela atmosfera celeste e luz refletida pelos elementos do entorno, admitida no interior edificado (ABNT, 2005a). Conforme Baker, Fanchiotti e Steemers (1998), a iluminação natural possui um importante papel para o melhor desempenho das funções biológicas, além de oferecer aos usuários senso de orientação, de tempo e das condições meteorológicas externas, o que gera melhor qualidade de vida e saúde. Conforme Lamberts, Dutra e Pereira (2014), o consumo de energia elétrica para a iluminação artificial em uma residência brasileira equivale a $14 \%$ do total consumido. Para uma residência na região Sudeste, esse percentual sobe para 19\%. Além das questões associadas ao conforto humano, é possível reduzir o consumo de energia elétrica ao inserir luz natural de forma adequada em um projeto arquitetônico, por diminuir o uso de iluminação artificial.

Em edifícios inseridos em áreas urbanas, a admissão da luz natural depende de uma série de variáveis como o tipo e as dimensões das aberturas, os dispositivos de sombreamento, as refletividades, a orientação geográfica e a relação do sistema com seu entorno (CINTRA, 2011; FROTA, 2004; MORAES; SCARAZZATO, 2003). Segundo Leder e Pereira (2008), os edifícios inseridos em cenários urbanos apresentam significativa redução de luz natural em seus ambientes internos em função da obstrução do céu devido, principalmente, aos cenários mais densos com ocupação máxima. Em contraposição, Araújo e Cabús (2007) afirmam que, em certas ocasiões, a luz refletida do entorno edificado contribui para o aumento da quantidade de luz no ambiente interno. Santos, Auer e Souza (2017) referendam a importância das configurações dos cânions urbanos no acesso à luz natural.

De acordo com Assis (2005), a legislação como variável condicionante da forma urbana está diretamente associada à mudança climática local e, dessa forma, deveria assumir critérios capazes de garantir o acesso à luz natural, entre outros. De acordo com Laranja, Gazzaneo e Cabús (2009) as regulamentações edilícias e urbanas têm como objetivo oferecer melhores condições na qualidade de vida da população, por isso se destaca a importância de um planejamento urbano que considere, entre outros fatores, o estudo da iluminação natural. Os parâmetros urbanísticos definidos pelas legislações municipais muitas vezes não garantem a disponibilidade de luz natural adequada, visto que a influência das obstruções externas (tanto naturais quanto edificadas) não é considerada, além das características climáticas locais, trajetória solar e tipos de céu (LARANJA; GAZZANEO; CABÚS, 2009).

Nas últimas décadas, houve crescimento da urbanização em diversos centros urbanos brasileiros, inclusive em Belo Horizonte, MG. Em Belo Horizonte, especificamente, a análise de mapas da Prefeitura Municipal indica que esse crescimento urbano foi feito predominantemente por edificações residenciais (PREFEITURA..., 2007, 2011). Os parâmetros urbanísticos municipais, especificamente afastamentos mínimos laterais e de fundos associados às características topográficas da malha urbana levaram a crer que a quantidade de luz natural admitida nos ambientes residenciais, especialmente em andares inferiores, vem sendo reduzida.

O objetivo deste trabalho é analisar a influência do entorno em ambientes urbanos de diferentes topografias na disponibilidade de luz natural a partir dos requisitos do RTQ-R (INSTITUTO..., 2012) e da NBR 15575-1 (ABNT, 2013) para um edifício residencial desenvolvido de acordo com a legislação urbanística do município e comparar os resultados obtidos pelos requisitos propostos por esses dois instrumentos normativos.

\section{Referencial teórico}

Existem fatores, tanto internos ao ambiente em estudo quanto externos a ele, que interferem na iluminação natural. De acordo com Robbins (1986) e Capeluto (2003), a disponibilidade de luz natural no ambiente interno depende das dimensões físicas do ambiente analisado, como profundidade e altura do pé-direito, características do sistema de iluminação natural (dimensões da janela, refletividade do vidro, esquadria) e textura/cor das superfícies internas.

Estudos indicam que não considerar a dinâmica da distribuição de luminâncias do céu e a reflexão do entorno obstruidor para a avaliação da luz natural representa uma grande distorção nos resultados (PEREIRA; PEREIRA; CLARO, 2008). Araújo e Cabús (2007) avaliaram a contribuição das reflexões da radiação solar das edificações vizinhas para a iluminação natural do ambiente interno. Os autores defenderam que, em áreas urbanas onde a tipologia de cânions é predominante, a luz refletida tem maior contribuição para a iluminação natural do que a luz difusa ou direta do céu. Verificou-se que a fachada sul apresentou grandes valores de 
iluminância devido à contribuição da parcela de luz refletida pela fachada vizinha oposta, no caso, a norte. Já para a fachada leste, notou-se que os maiores valores de iluminância foram encontrados no período da tarde devido à luz refletida pela fachada oeste. É interessante destacar a relação entre as alturas dos cânions para a disponibilidade de luz natural: quanto maiores os ângulos verticais de obstrução (AVO), menor será o valor encontrado de iluminância no ambiente interno. Vale ressaltar que esse estudo foi desenvolvido apenas para simulação de um dia do ano e para duas orientações.

Assim como Araújo e Cabús (2007), Pereira, Pereira e Claro (2008) também consideraram que a reflexão do entorno é uma parcela significativa para o cálculo de iluminação natural. De acordo com o estudo, os resultados demonstraram uma contribuição média das reflexões das edificações vizinhas de 26\%. Esse valor está relacionado à diferença entre as iluminâncias encontradas na superfície do modelo de abóbada inteira (plano horizontal) e o de meia abóbada com o entorno (plano vertical).

Leder e Pereira (2008) desenvolveram um parâmetro capaz de contribuir na elaboração de legislações urbanísticas para melhor garantir iluminação natural em áreas urbanas, denominado de janela de céu preferível (JCP). Esse parâmetro, a partir de estudos que relacionam a contribuição de luz natural devida de cada parcela da abóbada celeste com o cosseno do ângulo de incidência e seu fator de redução da iluminação juntamente com as frequências de visibilidade do céu, define a melhor área da abóbada celeste visível no ambiente interno para aumentar o potencial da iluminância a partir da luz natural. Dessa forma, é possível otimizar a iluminação natural utilizando essas áreas com maiores potenciais da iluminância.

Acerca da influência dos parâmetros relacionados ao planejamento urbano, Santos, Auer e Souza (2017) avaliaram a iluminação natural em um cômodo localizado na cidade de Cuiabá e na pior situação: piso térreo de uma edificação em um contexto urbano denso, do tipo cânion urbano. O estudo apresentou variação na profundidade do ambiente, nas orientações geográficas, nas alturas das obstruções frontais e na largura da via. Das quatro variáveis, a profundidade foi a que apresentou a maior correlação com a métrica sDA (Spatial Daylight Autonomy), seguida da largura da via, da altura das obstruções e, por último, das orientações solares. Os autores também observaram que a fachada orientada para o norte possuía menores valores de sDA devido aos edifícios bloqueadores da luz solar direta, entretanto esses mesmos edifícios serviram de refletores da luz advinda de outras orientações. Eles reforçam a importância da refletância das fachadas na contribuição para a elevação dos valores de iluminância interna.

Além da influência das edificações, o entorno também apresenta obstruções naturais, como a topografia. Em cidades que apresentam declividades elevadas, as regiões são ocupadas sem a devida diferenciação e adequação dos parâmetros urbanísticos, resultando em edificações que prejudicam a disponibilidade de luz natural do entorno ou para si mesmas. Na literatura técnica, não foram encontrados estudos que correlacionassem a disponibilidade de luz natural e a ocupação em terrenos com altas declividades.

\section{Legislações urbanísticas de Belo Horizonte}

Belo Horizonte é a capital do estado de Minas Gerais, localizada na região Sudeste do Brasil. A cidade possui latitude $-19^{\circ} 55^{\prime} 15^{\prime}$ ” e longitude 4356’16”. Em seu tecido urbano é possível encontrar declividades acima de $30 \%$, inclusive em regiões com ocupações e loteamentos aprovados (PREFEITURA..., 2013).

A Lei $\mathrm{n}^{\circ}$ 7.166/1996, Lei de Parcelamento, Ocupação e Uso do Solo, em vigência, delimita a área urbana em zonas e estabelece parâmetros urbanísticos (PREFEITURA..., 1996). Para cada zona são definidos parâmetros urbanísticos que regulam a ocupação do solo. Entre esses parâmetros, os que afetam a volumetria do edifício são o coeficiente de aproveitamento (CA), a quota mínima de terreno por unidade habitacional (QT), a taxa de ocupação (TO), a altura máxima na divisa e os afastamentos mínimos frontais, laterais e de fundos.

A Lei $n^{\circ}$ 9.725/2009 (PREFEITURA..., 2009) institui o Código de Edificações do Município de Belo Horizonte e estabelece os parâmetros mínimos de área de vãos para iluminação e ventilação naturais, bem como a relação entre profundidade do ambiente com a altura de seu pé-direito, além das dimensões mínimas dos ambientes, entre outros. A Tabela 1 apresenta os parâmetros relativos aos compartimentos de quartos e salas das edificações residenciais multifamiliares. 
Tabela 1 - Parâmetros relativos aos compartimentos de quartos e salas das unidades privativas das edificações de uso residencial multifamiliares estabelecidos pelo Código de Edificações de Belo Horizonte

\begin{tabular}{l|c|c|c|c}
\hline Compartimentos & $\begin{array}{c}\text { Área } \\
\text { mínima } \\
\left(\mathbf{m}^{\mathbf{2}}\right)\end{array}$ & $\begin{array}{c}\text { Dimensão } \\
\text { mínima } \\
\mathbf{( m )}\end{array}$ & $\begin{array}{c}\text { Área mínima do vão de iluminação } \\
\text { e ventilação em relação à área do } \\
\text { piso do compartimento }\end{array}$ & $\begin{array}{c}\text { Pé-direito } \\
\text { mínimo (m) }\end{array}$ \\
\hline Estar & 12,00 & 2,40 & $1 / 6$ ou $1 / 5$ & 2,60 \\
Dormitórios & 8,00 & 2,00 & $1 / 6$ ou $1 / 5$ & 2,60 \\
\hline
\end{tabular}

Fonte: adaptada de Prefeitura Municipal de Belo Horizonte (2009).

\section{NBR 15575-1 - Norma de Desempenho de Edificações Habitacionais}

A NBR 15575-1 (ABNT, 2013) estipula níveis mínimos de iluminância natural nas habitações. Segundo a norma, as simulações para análise de desempenho e admissão de luz natural devem atender aos níveis de iluminância, medida em lux, para três categorias de desempenho, mínimo (M), intermediário (I) e superior (S), e de acordo com a tipologia de uso dos ambientes, sendo requerido nas áreas de permanência prolongada valor mínimo de 60 lx para desempenho M; mínimo de 90 lx para desempenho I e mínimo de 120 lx para desempenho S.

A NBR 15575-1 (ABNT, 2013) ainda determina que as obstruções externas, as orientações dos ambientes, suas diferentes posições nos andares dos edifícios residenciais, o dimensionamento das aberturas e o tipo de esquadrias dos sistemas de admissão de luz natural, além das características de transmitância dos vidros e refletividade das superfícies internas do ambiente, devem ser considerados na realização de cálculos.

Para procedimentos de análise do desempenho por simulação ${ }^{1}$ a NBR 15575-1 (ABNT, 2013) estipula que o desempenho lumínico do ambiente deve ser avaliado para um ponto central no ambiente, à altura de $75 \mathrm{~cm}$ do piso acabado, e que a simulação do desempenho deve ser feita para 23 de abril e 23 de outubro nos horários de 9h30 e 15 h30 para um céu com nebulosidade média (índice de nuvens de $50 \%)$.

Para os procedimentos de análise do desempenho lumínico através de cálculos manuais e de simulação, a norma NBR 15575-1 (ABNT, 2013) referencia os procedimentos da NBR 15215-3: Procedimento de cálculo para a determinação da iluminação natural em ambientes internos (ABNT, 2005c), e para se obter o nível de iluminação externa, a NBR 15215-2: Procedimentos de cálculo para a estimativa da disponibilidade de luz natural (ABNT, 2005b).

\section{RTQ-R - Regulamento Técnico da Qualidade do Nível de Eficiência Energética de edificações residenciais}

O Regulamento Técnico da Qualidade do Nível de Eficiência Energética de Edificações Residenciais (RTQ-R) é um instrumento técnico que apresenta o método, os requisitos e as ferramentas de análise para a avaliação do nível de eficiência energética de edificações residenciais. Um dos quesitos de análise é a bonificação pelo uso da iluminação natural, que pode contribuir em até 0,30 ponto em 6 pontos máximos do programa (até $5 \%$ da pontuação máxima do sistema). A avaliação desse requisito pode ser desenvolvida por método prescritivo ou por simulação computacional. $\mathrm{O}$ método de simulação computacional avalia a autonomia de luz natural a partir da criação de uma malha mínima de 25 pontos na altura da superfície de trabalho levando-se em conta o entorno do ambiente simulado. A comprovação do atendimento é dada para uma iluminância de 60 lx em 70\% da área do ambiente durante $70 \%$ das horas com luz natural no ano. Em ambientes com proteção solar, o percentual de área a ser atendida pela iluminação natural é reduzido para 50\% (INSTITUTO..., 2012).

Guedes (2012) abordou a análise da admissão de luz natural para três tipologias de edificações residenciais de padrões construtivos distintos. Concluiu que os parâmetros de área de aberturas equivalentes à área do piso, estabelecidos pelo Código de Edificações de Belo Horizonte, atendem facilmente aos requisitos estabelecidos pelo RTQ-R para a obtenção da pontuação máxima considerando a bonificação possível pelo uso adequado de iluminação natural. Entretanto, Guedes (2012) realizou seu estudo sem considerar edificações do entorno ou a influência da topografia.

${ }^{1} \mathrm{~A} A B N T$ se refere ao método de cálculo manual apresentado na NBR 15215-3 (2005c) como "simulação", no entanto cabe ressaltar

que não se trata de "simulação computacional" e, sim, de um método prescritivo. 


\section{Método}

O trabalho avaliou o desempenho do sistema de abertura vertical ante variações do entorno em um quarto e em uma sala de unidades residenciais multifamiliares através de cálculos matemáticos presentes nas partes 2 e 3 da NBR 15215 (ABNT, 2005b, 2005c) e por meio de simulações computacionais com o software Daysim 3.1-2012 (REINHART, 2012).

A avaliação por simulação foi feita para verificar o atendimento aos requisitos de autonomia da luz natural do RTQ-R (INSTITUTO..., 2012) e para avaliar o nível de iluminação natural no centro dos ambientes para a verificação do atendimento aos requisitos mínimos relativos à iluminação natural da NBR 15575-1 (ABNT, 2013).

\section{Características do tecido urbano}

O tecido urbano é de difícil representação porque é composto de diferentes tipologias edilícias, que, por sua vez, se combinam com outros elementos como topografia, configurações de lotes e arruamentos, o que gera muitas possibilidades de interferência para a disponibilidade de luz natural no ambiente interno (CINTRA, 2011).

A construção do modelo foi elaborada a partir de dados fornecidos pela Prefeitura de Belo Horizonte $(\mathrm{PBH})$, como mapas e informações técnicas dos projetos de loteamentos e edificações. Com esses dados, foram definidos a tipologia do tecido urbano e o modelo de edificação. As demais variáveis foram determinadas a partir de bibliografia sobre o assunto.

Para a seleção do tecido urbano, foram sobrepostos quatro mapas do município disponibilizados no site da PBH: mapa de bairros, mapa de declividade, mapa de tipologia de uso e ocupação, e mapa de zoneamento e áreas de diretrizes especiais do município. A partir dessa sobreposição, foram encontradas regiões na cidade com edifícios residenciais em topografias acidentadas e em zoneamentos urbanos de alto adensamento.

A partir da escolha da área, foi possível definir as dimensões dos lotes mais recorrentes na região. O site da PBH possui em seu banco de dados os projetos dos loteamentos aprovados com as dimensões de todos os lotes. Com base nessas informações, foi possível catalogar as dimensões dos lotes bem como sua área. Os lotes têm grande variação, mas é possível encontrar um padrão recorrente. Tanto os lotes de esquinas quanto os lotes remembrados (união de dois ou mais lotes contíguos) não foram considerados para esta pesquisa por não representarem situações críticas para a disponibilidade de luz natural.

A disponibilidade de luz natural para o ambiente interno em edifícios residenciais, depende, entre outros fatores, dos afastamentos e das alturas das construções vizinhas. Através da Lei nº 7.166/1996 (PREFEITURA..., 1996), é possível elaborar um estudo de viabilidade para um edifício residencial que contenha sua área construída, seus afastamentos e sua altura.

O modelo do edifício e entorno construído foi elaborado para duas zonas urbanas de grande representatividade no território municipal. Foram utilizados os parâmetros urbanísticos das zonas adensada (ZA) e de adensamento preferencial (ZAP), estabelecidas pela Lei $n^{0} 7.166 / 1996$. Essas duas zonas possuem alto potencial construtivo na cidade, conformando, dessa maneira, áreas com ambiente urbano adensado. A ZA e a ZAP possuem parâmetros urbanísticos semelhantes, o que resultou em modelos de edificações com características similares, sendo adotado, portanto, apenas um modelo de edificação para ambas.

Para a elaboração do modelo do edifício residencial utilizaram-se dimensões de lote recorrente no tecido urbano da área escolhida com $12 \mathrm{~m}$ frontais paralelos à rua e $30 \mathrm{~m}$ laterais, resultando em lote retangular com área de $360 \mathrm{~m}^{2}$. A partir da definição dos zoneamentos e das dimensões do lote, foi elaborado um estudo de viabilidade do potencial construtivo de acordo com os parâmetros urbanísticos definidos pela Lei $n^{\circ} \quad 7.166 / 1996$ (PREFEITURA..., 1996) e através de modelos de edifícios residenciais encontrados na cidade.

\section{Características do modelo da edificação e seu entorno}

O modelo do edifício foi definido com cinco pavimentos a partir do nível da rua, podendo ter níveis de subsolo destinados a estacionamento. O pavimento localizado ao nível da rua foi considerado como pilotis para utilização de estacionamento de veículos. Os quatro pavimentos superiores possuem duas unidades residenciais por pavimento, sendo uma voltada para a parte frontal do lote e outra voltada para a parte posterior, além da circulação central. As unidades residenciais do primeiro pavimento possuem área privativa descoberta projetada sobre os afastamentos laterais e de fundos, o que caracteriza uma laje ou terraço descoberto sobre o pavimento de estacionamento.

Uma vez que o entorno se integra aos mesmos parâmetros urbanísticos e regulatórios que o edifício-modelo, determinou-se para esses edifícios do entorno as mesmas características edilícias do 
modelo analisado, ou seja, mesmo terreno e mesmos afastamentos mínimos frontais, laterais e de fundos (Figura 1). Optou-se por elaborar modelos de edificações de acordo com a legislação atual por representar as possíveis configurações que o tecido urbano pode alcançar. Dessa forma, o estudo é capaz de demonstrar as permissividades e lacunas encontradas na legislação em vigência em Belo Horizonte.

\section{Características dos ambientes}

Determinou-se como objeto de análise a avaliação de um quarto e uma sala com janelas em fachadas diferentes inseridos na unidade residencial localizada na parte posterior do edifício modelo (Figura 1). Essa determinação partiu da premissa de que esses ambientes localizados na porção dos fundos e com entorno edificado de terrenos em declive podem apresentar maior obstrução do céu, tendo maior redução na admissão de luz natural.

O quarto analisado apresenta janela centralizada e localizada na fachada de fundos. A sala apresenta janela centralizada e localizada na fachada lateral. As dimensões desses ambientes foram definidas em atendimento ao Código de Edificações de Belo Horizonte (PREFEITURA..., 2009), que estabelece os parâmetros mínimos de área de vãos para iluminação e ventilação naturais, bem como a relação entre a profundidade do ambiente e a altura de seu pé-direito, além das dimensões mínimas para os ambientes internos. A Tabela 2 apresenta as dimensões adotadas para cada ambiente analisado. $\mathrm{Na}$ construção do edifício-modelo foram desconsiderados quaisquer elementos de controle de admissão de luz natural nas janelas ou nas fachadas, como cortinas, toldos, proteções, venezianas ou outros sistemas que pudessem eventualmente interferir na admissão da luz natural no ambiente.

\section{Características da topografia}

Determinaram-se quatro diferentes tipologias topográficas de declividade longitudinal do lote, caracterizadas neste trabalho como “i”, para a análise da disponibilidade de luz natural dos ambientes inseridos no edifício-modelo junto ao entorno edificado. As declividades definidas enquadram-se em declividades encontradas no tecido urbano da malha topográfica da cidade, equivalendo a $0 \%$ (terrenos planos), 10\%, 20\% e $30 \%$ (Figura 2). Não foi considerada neste trabalho a declividade transversal.

Figura 1 - Modelo tridimensional e planta de implantação do edifício-modelo analisado junto ao entorno edificado e localização dos ambientes
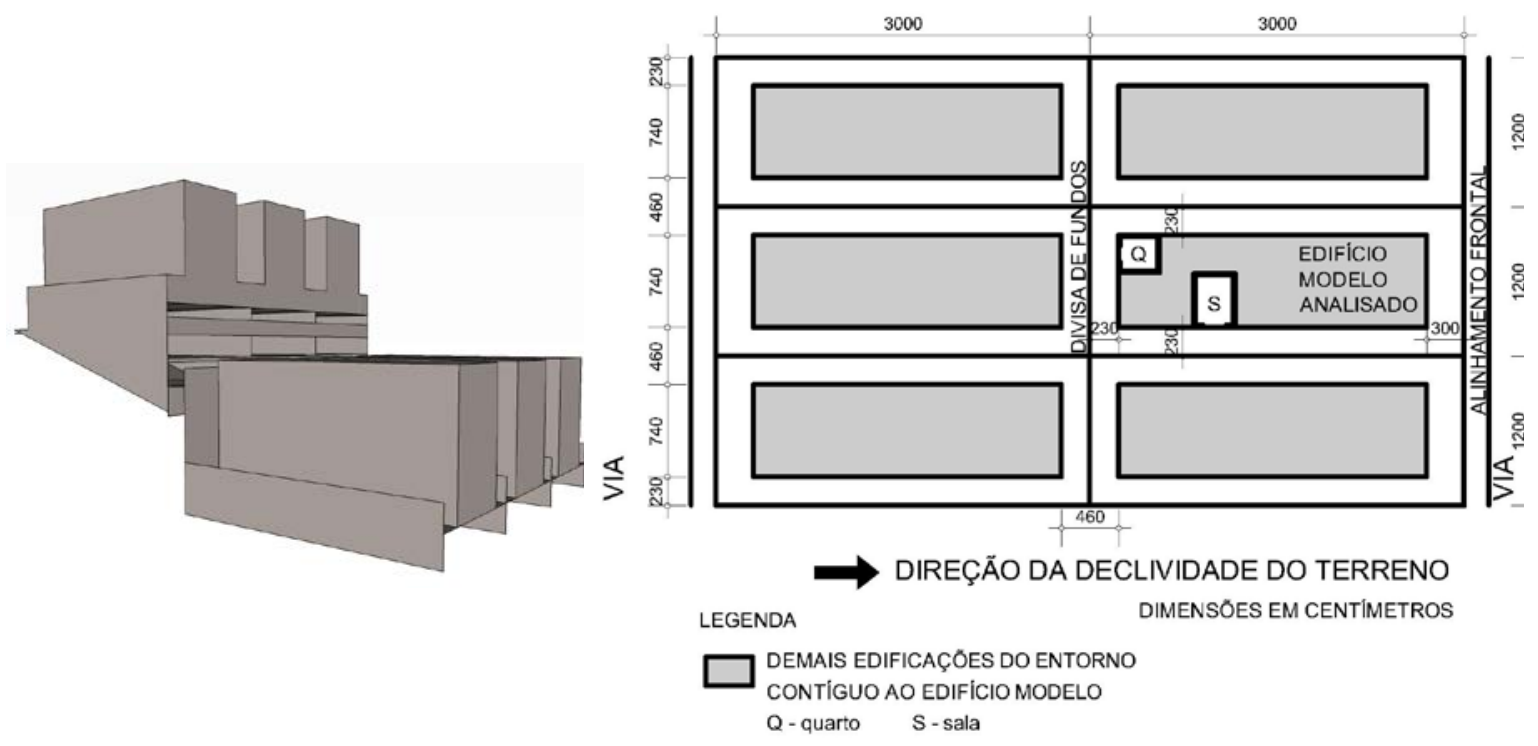

3000 3000

Tabela 2 - Dimensões dos ambientes

\begin{tabular}{l|c|c|c|c}
\hline Ambientes & $\begin{array}{c}\text { Largura } \\
\text { (m) }\end{array}$ & $\begin{array}{c}\text { Profundidade } \\
(\mathbf{m})\end{array}$ & $\begin{array}{c}\text { Dimensões janela largura } \\
\text { x altura/peitoril (m) }\end{array}$ & $\begin{array}{c}\text { Pé-direito } \\
\text { (m) }\end{array}$ \\
\hline Quarto & 2,70 & 3,00 & $1,20 \times 1,20 / 1,10$ & 2,60 \\
Sala & 3,00 & 4,00 & $1,70 \times 1,20 / 1,10$ & 2,60 \\
\hline
\end{tabular}

Fonte: adaptada de Prefeitura Municipal de Belo Horizonte (2009). 
Figura 2 - Cortes esquemáticos dos modelos i0 e i30
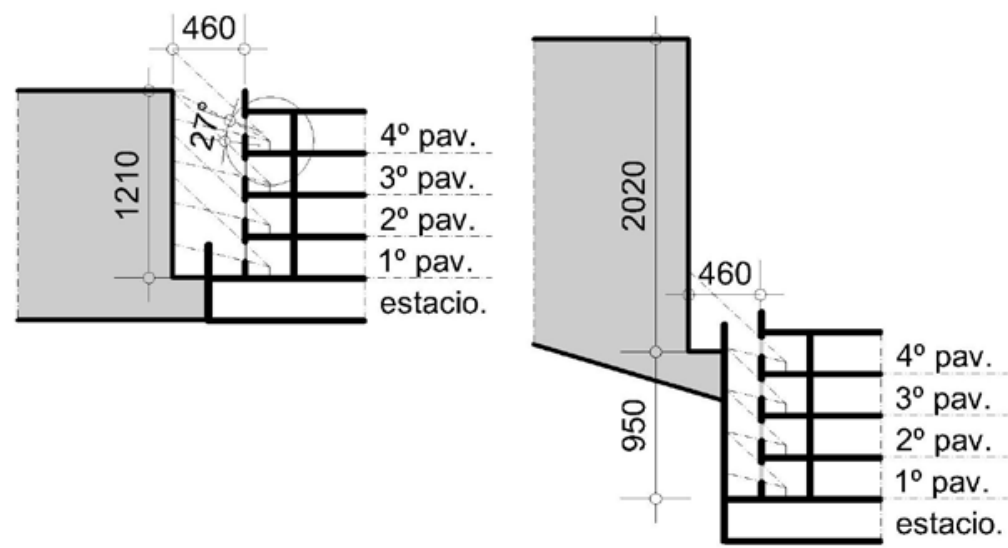

\section{Modelos analisados e nomenclatura}

Aos dois ambientes analisados do edifício modelo combinaram-se três variáveis: declividade longitudinal do terreno, localização vertical por pavimento e orientação geográfica das aberturas. Para facilitar a compreensão, cada um dos dois ambientes analisados apresenta em sua nomenclatura uma abreviação do nome de cada variável, partindo do seguinte formato: declividadepavimento-orientação. Exemplificando, o Modelo i30-pv1-N é um modelo cuja declividade do terreno é de $30 \%$ e localizado no primeiro pavimento com orientação da janela para o norte.

A Tabela 3 apresenta de forma resumida as três variáveis referentes à declividade, à localização vertical e à orientação geográfica, definidas e combinadas para cada um dos dois ambientes, resultando, portanto, em 64 modelos analisados por ambiente.

Os índices de refletância nos ambientes internos, de acordo com Capeluto (2003), foram de $20 \%$ para piso, $80 \%$ para teto e 65\% para paredes. De acordo com Leder, Pereira e Moraes (2007) e Capeluto (2003), adotou-se o índice de refletância do entorno edificado e dos muros de divisa de $40 \%$.

\section{Modelagem, software de simulação e dados de entrada}

A partir da definição do edifício-modelo bem como de seu entorno e das características físicas dos ambientes analisados e suas janelas, foram elaborados os modelos tridimensionais no programa SketchUp v. 8.0. Para a simulação computacional foi utilizado o programa Daysim 3.1-2012 (REINHART, 2012), que possibilita a verificação da iluminação natural de forma dinâmica para o período de 1 ano.

Diferentemente do artigo publicado por Guidi et al. (2017), que utilizou um arquivo climático do tipo
Inmet para as simulações computacionais em face da necessidade de se terem dados de nebulosidade para a análise do tipo de céu disposto intermediário (céu com nebulosidade média) na NBR 15575-1 (ABNT, 2013), no presente artigo foi utilizado o arquivo climático Swera de 8.760 horas da cidade de Belo Horizonte (LABEEE, 2016). O arquivo Inmet disponível apresentava dados constantes de nebulosidade (igual a 0,5); além disso, Fonseca, Fernandes e Pereira (2017) selecionaram os arquivos Swera para a confecção de proposta de zoneamento bioclimático referente à iluminação natural para o território brasileiro. De acordo com os autores, a escolha baseou-se na adequabilidade dos dados, visto que os arquivos Iwec são disponibilizados para poucas cidades do Brasil; os TRY são disponibilizados para 17 cidades, mas com dados com maior desvio se comparado ao Swera para radiação solar (SCHELLER et al., 2015); e os arquivos Inmet, que, por falta de dados disponíveis, adotam valores constantes para nebulosidade, opacidade do céu, visibilidade e altura de céu, importantes para descrever a disponibilidade de luz natural local.

\section{Requisitos de análise conforme a NBR 15575-1}

Para a análise dos requisitos da NBR 15575-1 (ABNT, 2013) foram obtidos os níveis de iluminância no centro do ambiente de três diferentes maneiras:

(a) pelo método de avaliação prescritivo (simulação) indicado na norma;

(b) por simulação computacional, usando-se o dia do arquivo climático estabelecido na norma; e

(c) por simulação computacional, usando-se o dia do arquivo climático com nebulosidade de 5 décimos mais próximo aos dias de análise estipulados na norma (índice de nuvens de 50\%). 
Tabela 3 - Declividade, orientação geográfica e localização do pavimento dos modelos construtivos analisados

\begin{tabular}{l|c|c|c|c}
\hline \multicolumn{1}{c|}{ Parâmetros } & Modelos i0 & Modelos i10 & Modelos i20 & Modelos i30 \\
\hline Declividade (i) (\%) & 0 & 10 & 20 & 30 \\
\hline Orientação geográfica & Norte, sul, & Norte, sul, & Norte, sul, & Norte, sul, \\
& leste, oeste & leste, oeste & leste, oeste & leste, oeste \\
\hline $\begin{array}{l}\text { Localização } \\
\text { vertical/pavamento (pv) }\end{array}$ & pv1, pv2, pv3 & pv1, pv2, pv3 & pv1, pv2, pv3 & pv1, pv2, pv3 \\
\hline
\end{tabular}

\section{Método de avaliação prescritivo indicado na NBR 15575-1}

O método proposto pela norma é do tipo estático, no qual se calcula a iluminância interna para determinado dia e horário. Para o método de avaliação conforme o critério de simulação pela NBR 15575-1 (ABNT, 2013), os cálculos devem seguir o estabelecido pela NBR 15215 - Partes 2 e 3 (ABNT, 2005b, 2005c), sendo a primeira para calcular a iluminância externa para um céu de nebulosidade média com índice de nuvens de 50\% e a segunda para calcular a iluminância em ambientes internos. Como a norma NBR 15215-2 não possui definição de tipo de céu feita por índice de nebulosidade, considerou-se para os cálculos um céu parcialmente encoberto. Vale ressaltar que foi considerada a correção horária para o dia 23 de outubro, uma vez que a cidade de Belo Horizonte adota o horário de verão brasileiro. Com as definições dos ângulos de declinação, altura e azimutes solares, foi possível encontrar a iluminância externa em um plano horizonte através da Equação 1 (ABNT, 2005b):

Echi $=0,30+45 * \operatorname{sen} \gamma \mathrm{s}$

Eq. 1

Onde:

Echi = iluminância externa horizontal para céu intermediário, em quilolux [klx]; e

$\gamma \mathrm{s}=$ altura solar, em graus.

Foram elaboradas as máscaras de obstrução para cada ambiente levando-se em consideração sua localização no pavimento e em qual modelo de declividade este está inserido. A partir das máscaras, foram encontrados os valores da componente celeste (CC), da componente refletida externa (CRE) e da componente refletida interna (CRI). Com esses valores encontra-se a contribuição de iluminação natural (CIN) (Eq. 2 (ABNT, 2005b)), que, multiplicada pela iluminância externa (Echi) (Eq. 3 (modificada de ABNT (2005b))), resulta no valor da iluminância do ponto interno (Ep).

$\mathrm{CIN}=(\mathrm{CC}+\mathrm{CRE}+\mathrm{CRI}) * \mathrm{KT} * \mathrm{KM} * \mathrm{KC}$ Eq. 2 Onde:
$\mathrm{KT}$ - transmissividade do vidro $=0,85$;

KM - fator de manutenção = 0,9; e

$\mathrm{KC}$ - fator de caixilho $=1,0$.

Ep $=($ CIN.Echi $) / 100 \%$

Eq. 3

\section{Simulação computacional usando-se o dia do arquivo climático estabelecido na NBR 15575-1}

A NBR 15575-1 (ABNT, 2013) estabelece que o desempenho lumínico deve ser verificado para os dias 23 de abril e 23 de outubro nos horários de 9h30 e 15h30, de forma a obter a iluminância mínima de 60 lx no ponto central do ambiente analisado. Como se considera que a metodologia por ela indicada e descrita no subitem anterior não é capaz de identificar adequadamente a influência da reflexão no cânion urbano, como demonstrado pelas máscaras apresentadas na Figura 4, adotou-se também a simulação computacional (considerada mais precisa) para se encontrar o valor da iluminância no ponto central do cômodo.

Portanto, foram realizadas simulações computacionais utilizando-se o mesmo programa Daysim 3.1-2012 (REINHART, 2012) com uma malha com um ponto central. Como a NBR 155751 (ABNT, 2013) determina os horários de 9h30 e 15h30, ou seja, horários intermediários das horas do arquivo climático, fez-se uma média entre os valores de $9 \mathrm{~h}$ e $10 \mathrm{~h}$ e entre os valores de $15 \mathrm{~h}$ e $16 \mathrm{~h}$. Dessa forma, encontrou-se o valor da iluminância do ponto central do ambiente analisado. Entretanto, observou-se no arquivo climático Swera que a nebulosidade para esses dias e horários não é de 5 décimos de céu, como determinado pela norma (ver Tabela 4).

\section{Simulação computacional usando-se o dia do arquivo climático com nebulosidade de 0,5 e mais próximo aos dias de análise estipulados na norma}

Para solucionar o problema da nebulosidade média encontrado no método descrito acima, propôs-se encontrar no arquivo climático os dias mais próximos dos estabelecidos pela norma com valores 
de nebulosidade média de 5 décimos de céu. O restante da metodologia é similar.

\section{Comparação dos dias de análise}

Abaixo segue a Tabela 4, dos dias analisados para verificação do atendimento aos requisitos da NBR 15575, com indicação das alturas solares, nebulosidades e iluminâncias difusas externas. Para a norma NBR 15215-2 foi interpretado que um índice de nuvens de $50 \%$ corresponderia ao céu intermediário.

Ao analisarem-se os níveis de iluminação externa usados para análise do atendimento ao requisito da NBR 15575-1 (ABNT, 2013), verifica-se que, como no arquivo Swera a nebulosidade média do dia 23 de abril para os horários de 9 h30 e 15 h00 é significativamente diferente daquela solicitada pela norma (índice de nuvens de 50\%), os valores de iluminância encontrados para dias com nebulosidades de 50\% (dias 18/abr e 10/mai) se mostraram significativamente mais próximos daqueles calculados através da NBR 15215-2 (ABNT, 2005b).

Já para 23 de outubro as nebulosidades de 65\% e de $70 \%$ encontradas no arquivo Swera são mais próximas à solicitada na norma. Portanto, para esse dia os valores de iluminância externa se mostraram mais condizentes com os calculados pela NBR 15215-2 (ABNT, 2005b) do que os valores obtidos para os dias 23 de setembro e 25 de outubro, dias de nebulosidades mais próximas a 50\%.

Ressalta-se que, quando se utilizam os dias estabelecidos na norma para a simulação computacional, buscados diretamente de determinado arquivo climático, há possibilidade de uma grande variação em relação aos valores de iluminância externa esperados pela norma, já que os dias do arquivo climático podem não possuir a cobertura de nuvens estabelecida. No caso de Belo Horizonte, essa diferença chegou a 57\%.

\section{Requisitos de análise conforme 0 RTQ-R}

Para a quantificação da autonomia de luz natural do RTQ-R (INSTITUTO..., 2012), a altura da malha de pontos nos ambientes foi determinada a $75 \mathrm{~cm}$ do piso. Foi definida uma malha de 90 pontos para o quarto e de 130 pontos para a sala. Foram consideradas variáveis internas e externas, variáveis relacionadas à localização geográfica do edifício analisado e variáveis relacionadas à atividade do ambiente. As variáveis internas incluem as dimensões físicas do ambiente analisado, a refletividade de superfícies internas e as características do sistema de iluminação natural (dimensões da janela e refletividade do vidro). As variáveis externas incluem a refletividade de superfícies e a composição volumétrica do entorno. As variáveis relacionadas à atividade do ambiente referem-se aos horários das atividades desenvolvidas no interior do ambiente utilizando exclusivamente a iluminação natural.

O horário de avaliação para a autonomia de luz natural correspondeu ao intervalo das 6 h00 às 18h00 de forma ininterrupta e equivalente à duração média do dia para a cidade de Belo Horizonte.

Tabela 4 - Dias analisados e dados de hora, altura solar (ํ), nebulosidade (0-10), iluminância externa (lux) do arquivo climático Swera

\begin{tabular}{|c|c|c|c|c|c|}
\hline Dias analisados & Dia & Hora & $\begin{array}{c}\text { Altura } \\
\text { solar }\left({ }^{\circ}\right)\end{array}$ & Neb (0-10) & $\begin{array}{l}\text { Iluminância } \\
\text { externa (lx) }\end{array}$ \\
\hline \multirow{4}{*}{$\begin{array}{l}\text { NBR 15575-1 - pela NBR } \\
15215-2\end{array}$} & 23/abr & $9 h 30$ & 41 & (céu int) & 29.137 \\
\hline & 23/abr & $15 h 30$ & 30 & (céu int) & 22.195 \\
\hline & 23/out & $9 h 30$ & 42 & (céu int) & 29.965 \\
\hline & 23/out & $15 \mathrm{~h} 30$ & 51 & (céu int) & 34.717 \\
\hline \multirow{4}{*}{$\begin{array}{l}\text { NBR } 15575-1 \text { - dia } \\
\text { estabelecido pela norma }\end{array}$} & 23/abr & 9 9h30 & 41 & $15 \%$ & 12.500 \\
\hline & 23/abr & $15 \mathrm{~h} 30$ & 30 & $100 \%$ & 30.100 \\
\hline & 23/out & $9 h 30$ & 42 & $65 \%$ & 34.000 \\
\hline & 23/out & $15 h 30$ & 51 & $70 \%$ & 32.850 \\
\hline \multirow{4}{*}{$\begin{array}{l}\text { NBR } 15575-1 \text { - dia mais } \\
\text { próximo com } \\
\text { nebulosidade igual ou } \\
\text { próxima a } 0,5\end{array}$} & 18/abr & $9 \mathrm{~h} 30$ & 43 & $50 \%$ & 28.250 \\
\hline & 10/mai & $15 h 30$ & 25 & $50 \%$ & 22.600 \\
\hline & 23/set & $9 h 30$ & 36 & $50 \%$ & 24.650 \\
\hline & 25/out & $15 h 30$ & 53 & $55 \%$ & 27.350 \\
\hline
\end{tabular}

Fonte: adaptada de ABNT (2013) e LABEEE (2016).

Através do programa Daysim 3.1-2012 (REINHART, 2012) foram gerados gráficos de avaliação da autonomia de luz natural de acordo com a malha determinada para os dois ambientes. $\mathrm{O}$ 
programa possui uma saída em dados numéricos que permite identificar quais pontos da malha atendem aos requisitos do RTQ-R (INSTITUTO..., 2012), ou seja, quais pontos possuem valores iguais ou superiores a $70 \%$ das horas simuladas. Para a avaliação do requisito do RTQ-R (INSTITUTO..., 2012) considerou-se, de forma simplificada, que cada ponto da malha equivaleria a uma porcentagem proporcional à área do ambiente. Para cumprir o atendimento ao regulamento técnico, o ambiente do quarto deveria possuir no mínimo 63 pontos dos 90 pontos totais com valores de autonomia de luz iguais ou superiores a $70 \%$, e o mesmo critério para 91 pontos da sala dos 130 pontos totais deste ambiente.

\section{Resultados e discussões}

Os resultados obtidos foram separados por cada norma e compilados em gráficos separados por pavimentos para facilitar a análise. Uma breve análise dos arquivos climáticos indicou que o arquivo Swera tende a apresentar valores em média $20 \%$ mais elevados de iluminância em relação ao arquivo Inmet usado por Guidi et al. (2017), o que elevou o percentual de atendimento ao RTQ-R no presente artigo.

\section{NBR 15575-1}

Para a NBR 15575-1 (ABNT, 2013) os resultados das análises foram para três diferentes metodologias: prescritiva, por simulação computacional, usando-se um arquivo climático Swera para os dias estabelecidos na norma, e por simulação computacional para os dias com nebulosidade mais próxima a 50\%.

Para a metodologia prescritiva, foram elaboradas máscaras de obstrução de acordo com a NBR 15215-3 (ABNT, 2005b). Observa-se que pelo método de cálculo da NBR 15215-3 (ABNT, 2005c), quando não há componente celeste a ser calculada, a componente refletida externa será igual, independentemente da altura do pavimento, pois o método não é capaz de considerar as interreflexões do cânion urbano, uma vez que leva em conta apenas uma reflexão entre o céu e a superfície oposta (Figura 3), conforme indica Souza (1997).

Observou-se, através das máscaras construídas para os ambientes (Figura 4), que, para as salas, apenas aquelas situadas no quarto pavimento, em todas as declividades de terreno, apresentaram parcela de céu vista a partir do ponto interno. A componente refletida externa (CRE) calculada pelo método da NBR 15575 fornece valores iguais para os demais casos. Já os únicos quartos que apresentaram parcela de céu vista são aqueles localizados no quarto pavimento do modelo de declividade $0 \%$. Os outros ambientes apresentaram máscaras com obstrução da fachada da edificação oposta em toda a abertura e, portanto, valores semelhantes de CRE.

A partir dessas máscaras, foram encontrados os valores da iluminância no ponto central do ambiente. Para possibilitar uma comparação visual dos resultados, as Figuras 5 a 7 representam os valores encontrados para esse ponto no centro geométrico dos quartos e salas para o primeiro e o quarto pavimentos. Como o interesse deste trabalho é verificar o atendimento mínimo aos requisitos da norma, o valor máximo indicado da escala gráfica adotada nas figuras é de 1.000 lx. No entanto, ressalta-se que foram encontrados valores bastante superiores a esses para certos dias e horários.

Pelo método prescritivo indicado na NBR 15575 (Figura 5), todos os valores dos pontos centrais dos ambientes de quarto e sala atenderam ao nível superior de desempenho estabelecido na norma (iluminâncias superiores a $120 \mathrm{~lx}$ ), sendo o valor mínimo calculado de 248 lx, e o máximo de 4.850 lx.

Figura 3 - Porção de céu “vista” através de uma superfície refletora

Fonte: Souza (1997).

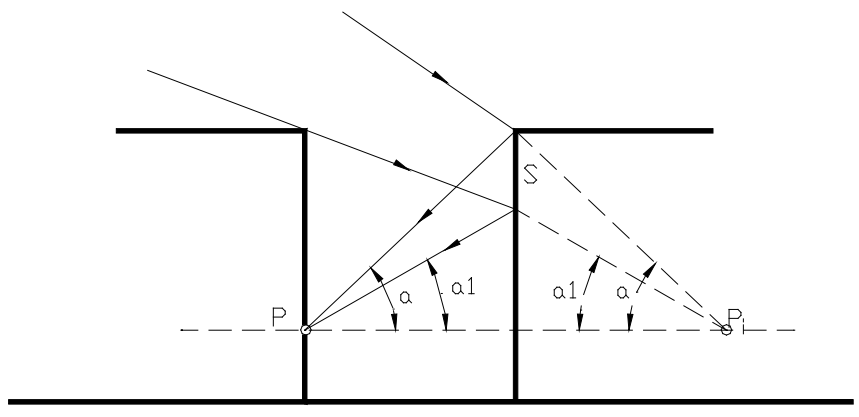


Figura 4 - Máscaras dos ambientes analisados onde se observam as obstruções pela CRE, as parcelas de céu vistas pela CC e a CRI
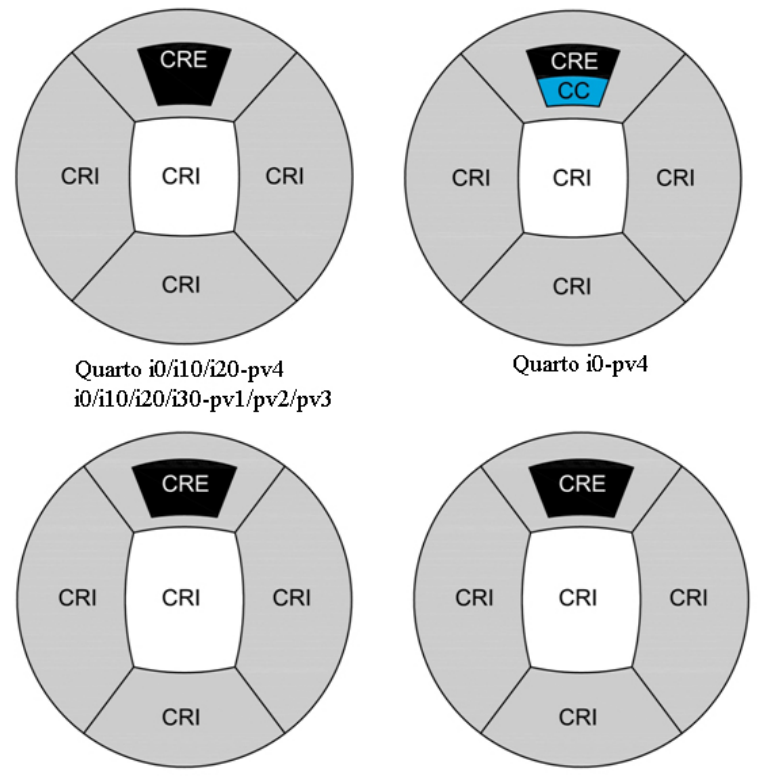

Sala i0/10/20/30

Sala i0/10/20/i30-pv4

pv1/pv2/pv3

Nota: ${ }^{*} \mathrm{CC}$, componente celeste; $\mathrm{CRI}$, componente refletida interna; e CRE, componente refletida externa de acordo com a NBR 15215-3 (ABNT, 2005C).

Figura 5 - Iluminâncias obtidas pelo método prescritivo da NBR 15575

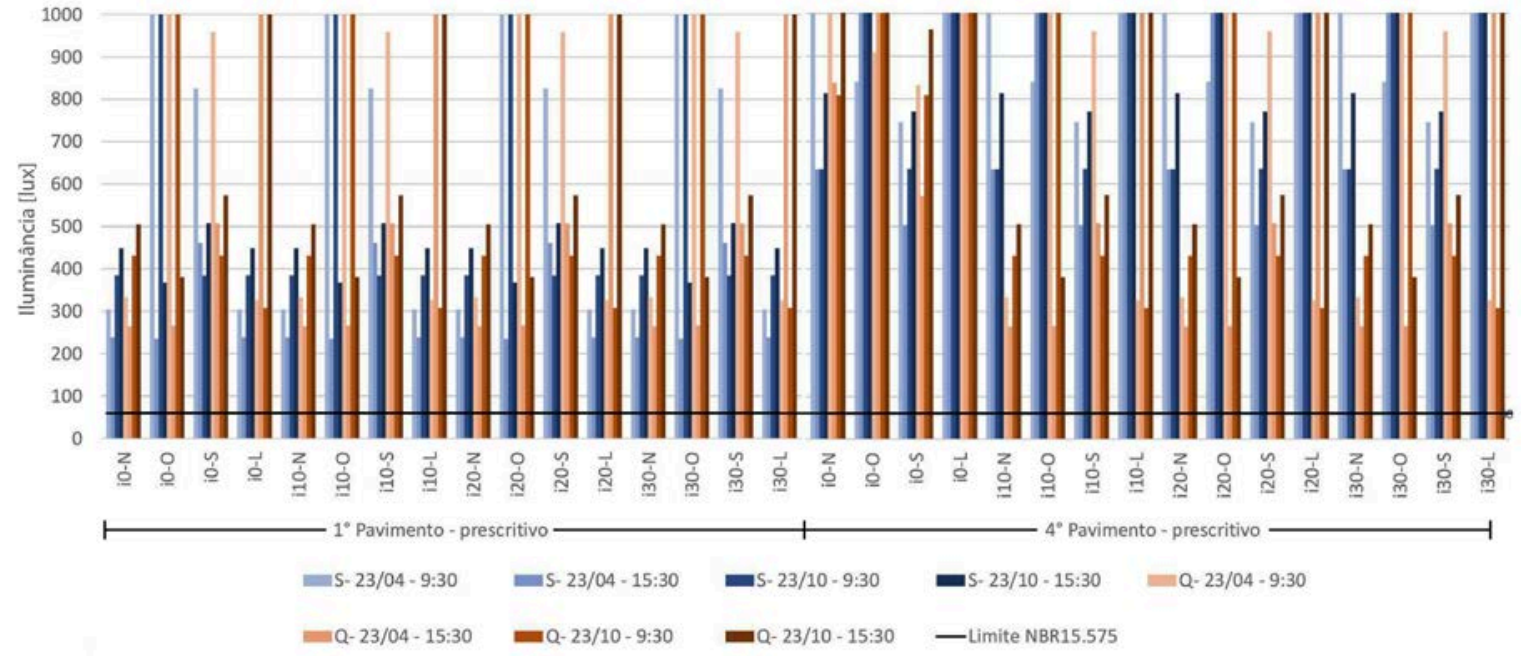


Figura 6 - Iluminâncias obtidas por simulação computacional para os dias estabelecidos na NBR 15575-1 (ABNT, 2013)

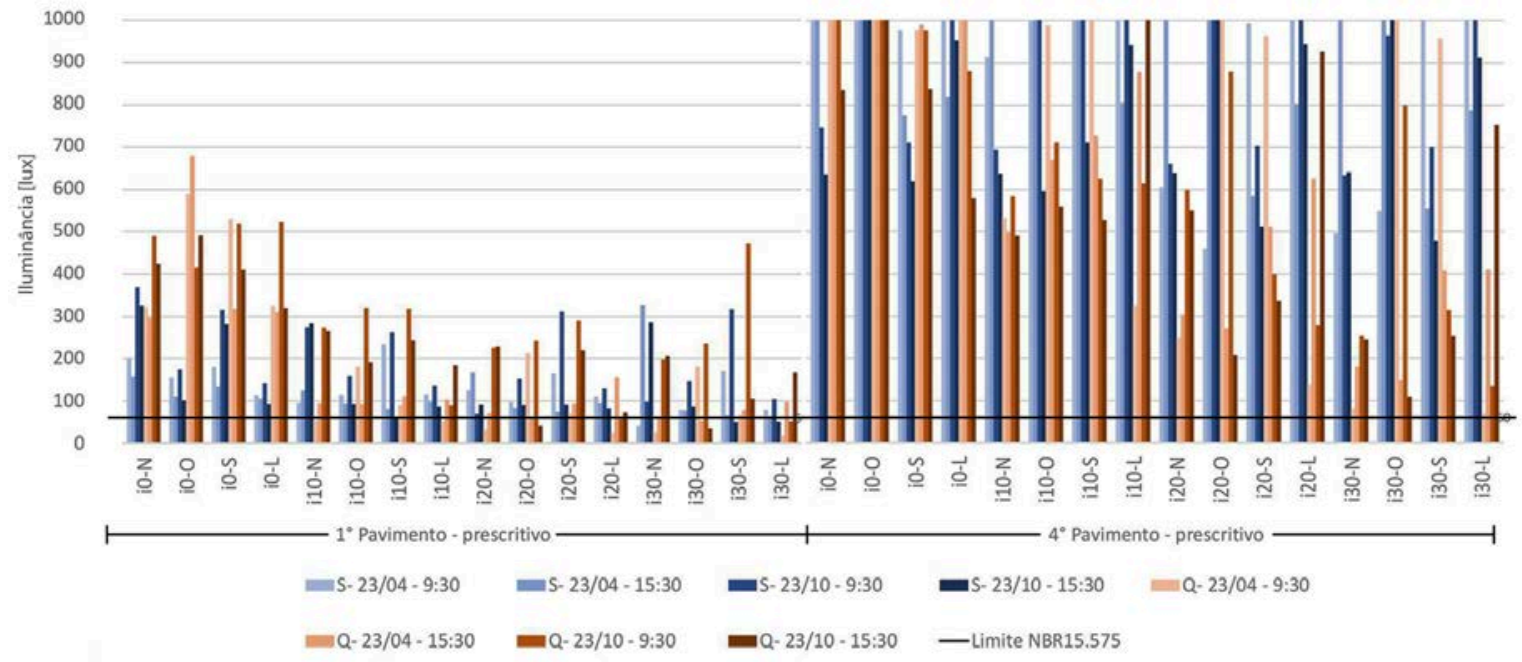

Figura 7 - Iluminâncias obtidas por simulação computacional para os dias de nebulosidade média

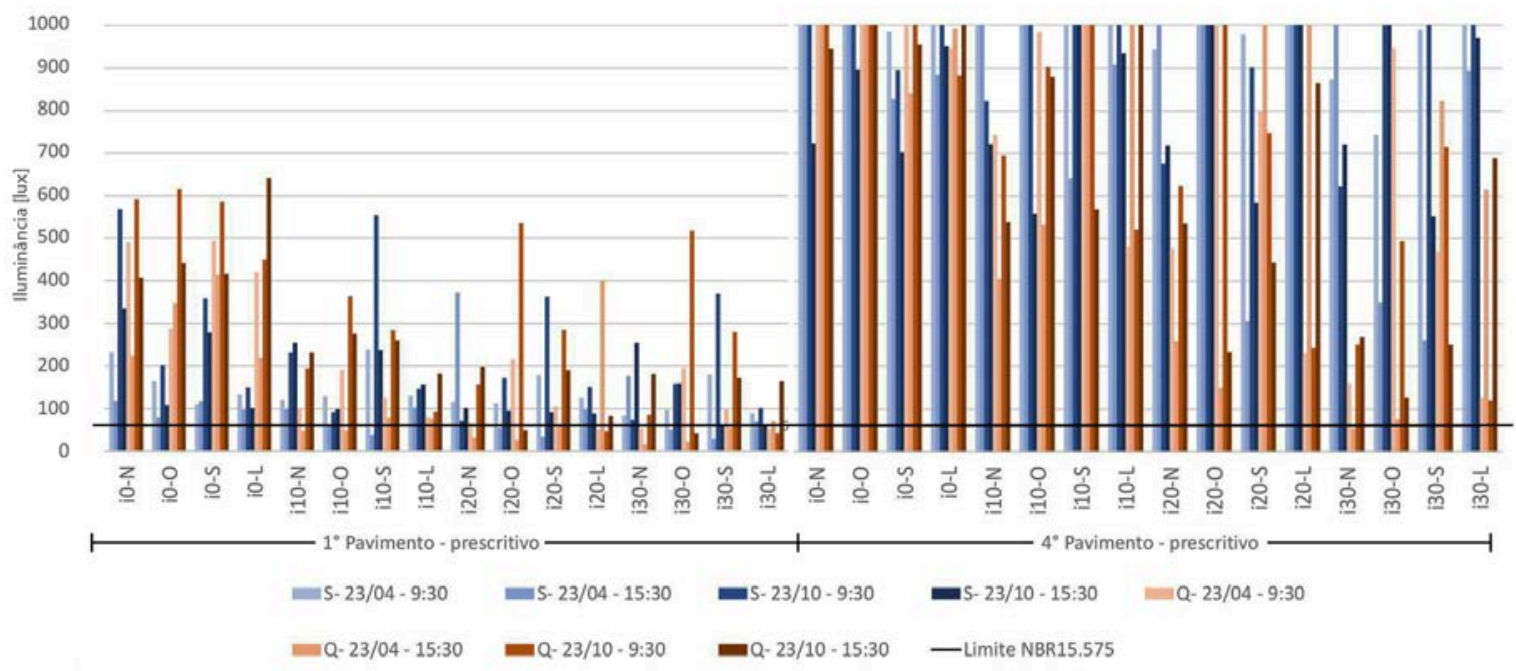

Já por simulação computacional, verifica-se menor percentual de atendimento à NBR 15575, especialmente nos pavimentos inferiores. Para os dias 23 de abril e 23 de outubro (dias estipulados na norma), todos os ambientes do quarto pavimento atendem ao desempenho mínimo estabelecido pela norma. Já para o primeiro pavimento o requisito mínimo de 60 lx é atendido para $97 \%$ dos valores obtidos para as salas e para $81 \%$ dos valores obtidos para os quartos (Figura 6). Para as salas localizadas nas maiores declividades do primeiro pavimento o atendimento foi de $88 \%$, enquanto para os quartos o atendimento foi de $69 \%$.

Se forem considerados os dias de nebulosidade média, o requisito mínimo só não é atendido no $4^{\circ}$ andar para o quarto com abertura voltada para norte no terreno de $30 \%$ de inclinação, no qual se obtiveram 54 lx. Já para o primeiro pavimento temse que o requisito mínimo é atendido para apenas $89 \%$ dos valores obtidos para as salas e para $77 \%$ dos valores de iluminância obtidos para os quartos (Figura 7).

Verifica-se que o método apresentado na NBR 15215-3 (aqui denominado de prescritivo) não permite verificar o efeito da topografia, já que o valor de iluminância se mantém constante nos pavimentos que recebem apenas luz refletida do entorno $\left(1^{\circ}, 2^{\circ}, 3^{\circ}\right.$ pavimentos), com a diferença de valores ocorrendo apenas quando há ou não visão de céu ( $4^{\circ}$ pavimento) tanto em quartos quanto em salas.

Já nas avaliações feitas por simulação computacional é possível verificar-se a influência da topografia. Para os dias estabelecidos na norma 
(23 de abril e 23 de outubro) e para os dias de $50 \%$ de cobertura de nuvens no terreno sem inclinação, todos os ambientes atendem ao nível mínimo de 60 lx. Já para as topografias de $10^{\circ}, 20^{\circ}$ e $30^{\circ}$, o percentual de atendimento diminui à medida em que a inclinação do terreno aumenta. Para os dias estabelecidos na norma nas declividades i10 e i20, todas as salas atendem ao nível mínimo, enquanto $88 \%$ e $69 \%$ dos quartos nas respectivas declividades apresentam o atendimento. Para a declividade i30, a sala apresenta $88 \%$ do atendimento, enquanto o quarto apresenta 69\%. Para os dias de nebulosidade média, a sala apresenta atendimento em 94\%, 88\% e $75 \%$ para as declividades de i10, i20 e i30 respectivamente. Já os quartos apresentam atendimento inferior em relação às salas de $88 \%$, $63 \%$ e $56 \%$ para as mesmas declividades.

\section{RTQ-R}

Através dos resultados apresentados na Figura 8 foi possível verificar os percentuais de área dos ambientes de quarto e sala que atenderam à exigência de 60 lx em 70\% do tempo de uso com iluminação natural. Todas as variáveis analisadas (localização do ambiente verticalmente, orientação da abertura e declividade do terreno) apresentaram influência para a disponibilidade de luz natural no ambiente interno.

Foram feitas 64 simulações computacionais para cada ambiente, em que se variaram as quatro orientações geográficas, os quatro pavimentos e as quatro declividades do terreno.

A partir da análise dos gráficos verificou-se que apenas 25\% dos quartos e $12,5 \%$ das salas localizados no primeiro pavimento atenderam ao requisito para a bonificação do RTQ-R (INSTITUTO..., 2012) e que os ambientes que tiveram atendimento estão localizados nos modelos de declividade $0 \%$. Isso se deve ao fato de o primeiro pavimento ter maiores obstruções do entorno.

É interessante observar que os valores de autonomia de luz natural das salas a partir da declividade de $20 \%$ são sempre superiores aos valores dos quartos, o que demonstra a influência da topografia neste último ambiente para a redução do atendimento. Entretanto, as salas do primeiro pavimento no modelo de declividade $0 \%$ apresentam valores inferiores aos dos quartos por apresentarem maior obstrução horizontal (fachada lateral do edifício vizinho obstruidor).

\section{Figura 8 - Percentual de área dos ambientes de quarto e sala que atendem a $70 \%$ das horas anuais com} 60 Ix, requisitos do RTQ-R, por declividade e por orientação geográfica por pavimento
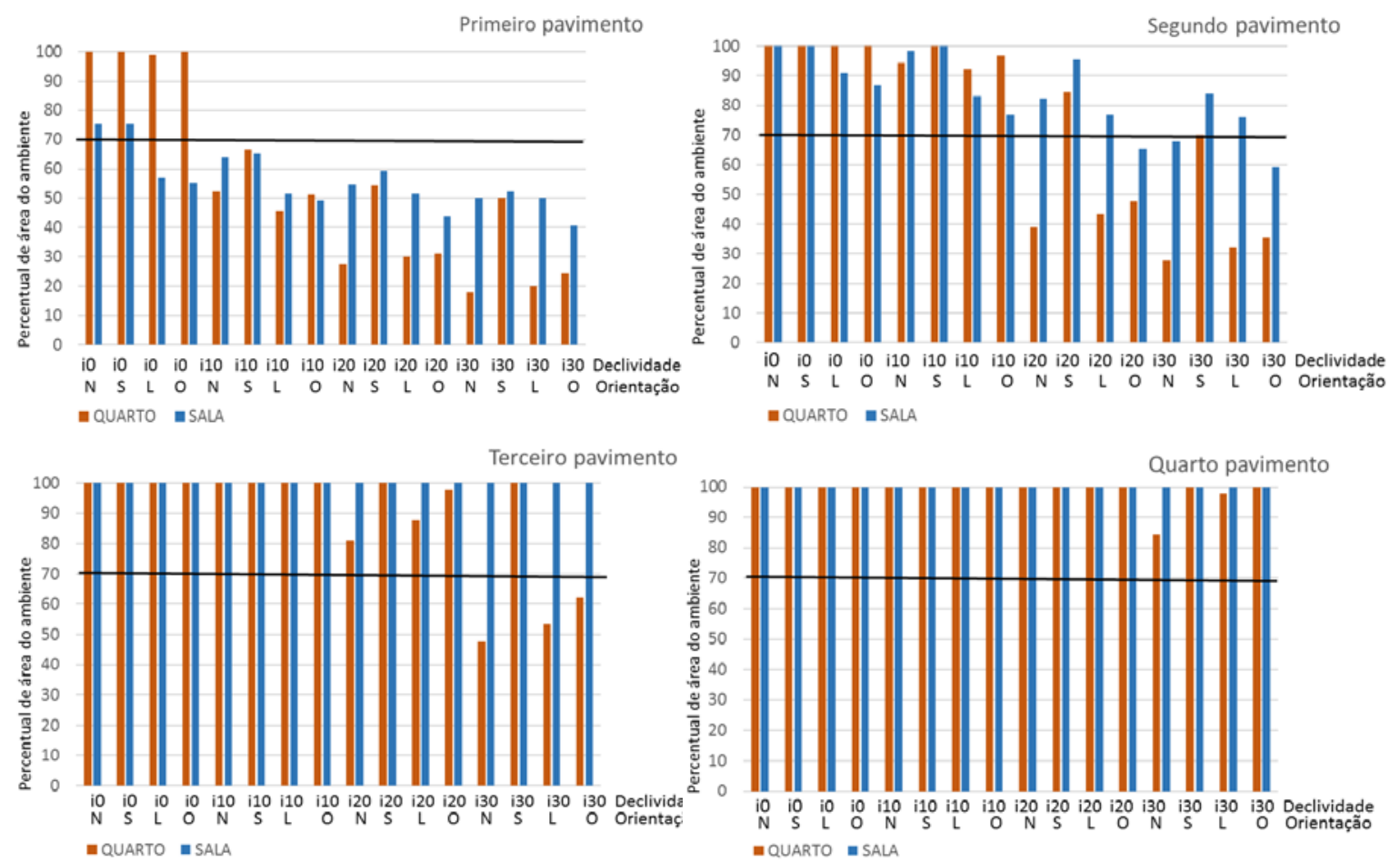
Em relação à localização vertical, é relevante observar que, à medida que os ambientes analisados passam a localizar-se em pavimentos mais elevados, a autonomia de luz amplia-se devido à redução da obstrução do céu, o que favorece a admissão da luz natural. No primeiro pavimento, 19\% dos ambientes atenderam ao requisito do RTQR (INSTITUTO..., 2012). Para o segundo e terceiro pavimentos o atendimento foi de respectivamente $72 \%$ e $91 \%$. No quarto pavimento todas as situações de ambientes com integração entre as variáveis topografia e orientação atenderam ao critério de 60 lx em 70\% do tempo de uso com iluminação natural. Isso demonstra que os parâmetros do Código de Edificações (PREFEITURA..., 2009), que estabelece a relação de $1 / 6$ da área do piso para o vão de abertura, atendem aos requisitos do RTQ-R (INSTITUTO..., 2012) nas situações de pouca obstrução do entorno.

Os resultados mostraram que os ambientes com orientação sul em todos os modelos de declividade apresentaram maior autonomia de luz natural em comparação com as demais orientações devido à admissão de luz natural potencializada pela contribuição da parcela de luz refletida pelo entorno, sendo, neste caso, a parcela refletida da fachada norte do edifício posicionado em frente a essas janelas. Essa diferença se torna maior nos modelos de declividade de $20 \%$ e $30 \%$, por apresentarem maiores obstruções externas e, consequentemente, maiores parcelas de luz refletida. Portanto, a refletância do entorno é uma importante fonte de contribuição para a iluminação natural.

Em relação à topografia os resultados apresentaram um padrão de redução da autonomia de luz natural em função da declividade do terreno. Quanto maior a declividade do terreno, menor a admissão de luz natural no ambiente interno com entorno edificado. Para o modelo topográfico i0, correspondente aos terrenos planos, 93,75\% dos ambientes atenderam ao requisito, enquanto para o modelo i10 esse número foi de $75 \%$. Os modelos i20 e i30 apresentaram respectivamente uma taxa de atendimento de $62,5 \%$ e $50 \%$.

\section{Comparação de resultados dos métodos}

Para melhor visualização e comparação os resultados foram compilados em uma tabela com o percentual de atendimento para os ambientes quarto e sala nas declividades i0 e i30 para o primeiro e o quarto pavimentos (Tabela 5).

A Tabela 5 mostrou claramente que o método prescritivo da NBR 15575 não é capaz de analisar adequadamente situações em que a luz chega aos ambientes internos por meio de reflexões no cânion urbano. Verificou-se ainda que entre os dois métodos de simulação computacional para a norma, os dias de nebulosidade média apresentaram percentuais de atendimento inferiores aos dos dias especificados na norma quando não há $100 \%$ de atendimento. Já pelo método de bonificação do RTQ-R, considerado mais preciso por levar em conta o clima luminoso de um ano completo, o atendimento foi inferior àquele obtido para a NBR15575, exceto para o quarto i30-pv4.

Observou-se também que por simulação computacional foi possível verificar que para o quarto, por sofrer maior influência da declividade longitudinal do terreno, obtiveram-se menores percentuais de atendimento que para a sala, que, localizada na fachada lateral, sofreu influência reduzida da declividade do terreno no presente estudo de caso.

Tabela 5 - Resultados compilados dos quatro métodos de cálculo da iluminação do percentual de atendimento para os ambientes quarto e sala nas declividades i0 e i30 para o primeiro e o quarto pavimentos

\begin{tabular}{l|c|c|c|c}
\hline \multicolumn{5}{c}{ Quarto } \\
\hline $\begin{array}{l}\text { Inclinação/ } \\
\text { pavimento }\end{array}$ & $\begin{array}{c}\text { Prescritivo - } \\
\text { NBR 15575 }\end{array}$ & $\begin{array}{c}\text { Simulação computacional } \\
\text { para os dias estabelecidos - } \\
\text { NBR 15575 }\end{array}$ & $\begin{array}{c}\text { Simulação computacional } \\
\text { para os dias de nebulosidade } \\
\text { média - NBR 15575 }\end{array}$ & $\begin{array}{c}\text { Simulação } \\
\text { computacional . } \\
\text { RTQ-R }\end{array}$ \\
\hline i0-pv1 & $100 \%$ & $100 \%$ & $100 \%$ & $100 \%$ \\
i30-pv1 & $100 \%$ & $69 \%$ & $56 \%$ & $0 \%$ \\
i0-pv4 & $100 \%$ & $100 \%$ & $100 \%$ & $100 \%$ \\
i30-pv4 & $100 \%$ & $100 \%$ & $94 \%$ & $100 \%$ \\
\hline \multicolumn{7}{r|}{ Sala } & & $50 \%$ \\
\hline i0-pv1 & $100 \%$ & $100 \%$ & $75 \%$ & $0 \%$ \\
i0-pv4 & $100 \%$ & $81 \%$ & $100 \%$ & $100 \%$ \\
i30-pv4 & $100 \%$ & $100 \%$ & $100 \%$ & $100 \%$ \\
\hline
\end{tabular}




\section{Conclusão}

A partir dos resultados, observa-se que foi alcançado o objetivo de estabelecer a análise da disponibilidade de luz natural para os dois ambientes do modelo proposto em suas variações de declividade do terreno, orientações de janelas e localização vertical da unidade. Observou-se primeiramente que a seleção do arquivo climático é relevante para a adequação e avaliação do cumprimento normativo, pois ele apresenta dados diferentes, com capacidade de influenciar a avaliação da disponibilidade de luz natural local. Indica-se que o arquivo climático Swera apresentou, em média, os valores de iluminância $20 \%$ mais altos em relação ao arquivo climático Inmet. Isso gerou um atendimento em área dos ambientes em média $22 \%$ superior àquele encontrado por Guidi et al. (2017).

O trabalho apresentou os parâmetros regulatórios de avaliação de iluminação natural de unidades residenciais no contexto brasileiro, especificamente no município de Belo Horizonte, MG. O estudo apresentou que, para um edifício-modelo com entorno edificado denso criado a partir das características urbanísticas e regulatórias dessa cidade, aproximadamente $81 \%$ dos ambientes simulados no primeiro pavimento não apresentaram autonomia de luz para atender aos critérios de bonificação do RTQ-R (INSTITUTO...., 2012). Nesse sentido, considera-se que o atendimento aos parâmetros urbanísticos regulatórios e mínimos para o dimensionamento dos vãos para iluminação não se mostrou suficiente para garantir níveis adequados de iluminação.

A declividade longitudinal do terreno mostrou-se inversamente proporcional à admissão de luz natural nos ambientes; contrariamente, a localização vertical do ambiente no edifício mostrou-se diretamente proporcional. Nas condições analisadas verificou-se que os parâmetros de declividade de terrenos e de cota altimétrica dos ambientes poderiam contribuir como critérios adicionais para a avaliação de admissão de luz natural pela legislação urbana municipal.

Em cenários urbanos densos, as obstruções externas à abertura da janela podem contribuir para o acesso à luz natural no ambiente interno quando ela está sendo diretamente iluminada, como no caso da fachada sul, que recebe luz refletida da fachada norte do edifício vizinho, análise coerente com as observações de Araújo e Cabús (2007), Pereira, Pereira e Claro ( 2008) e Santos, Auer e Souza (2017).
As análises desenvolvidas no presente artigo indicaram ainda que, usando-se um arquivo climático com dados reais, não é possível obter o dia especificado na norma NBR 15575-1 (ABNT, 2013) com a cobertura de nuvens requerida para a avaliação de desempenho da iluminação natural.

Tem-se ainda que a comparação entre os resultados obtidos para a NBR 15575-1 (ABNT, 2013) sugere que o método prescritivo apresentado na NBR 15215-3 (2005c), indicado pela NBR 15575-1 (ABNT, 2013), tende a apresentar valores superestimados de iluminância quando em situação de cânion urbano, no qual a obstrução do entorno é significativa se comparado a valores obtidos por simulação computacional, considerada mais precisa. Isso leva a crer que ambientes potencialmente mais escuros, como os quartos em pavimentos inferiores de cânions urbanos, possam ser considerados como atendendo a níveis mínimos de iluminação natural quando, na verdade, podem ser bastante sombrios. Essa análise é corroborada pelo baixo atendimento aos requisitos do RTQ-R (INSTITUTO..., 2012), que utiliza simulação dinâmica para todo o ano.

Nesse sentido, admite-se que os instrumentos institucionais regulatórios da admissão de iluminação natural do município de Belo Horizonte deveriam ser revisados, incluindo a análise da declividade de terrenos associada aos afastamentos. Acredita-se que uma proposição de ampliação de afastamentos para terrenos que apresentam declividades elevadas poderia atender a melhores níveis iluminação natural. Os resultados do trabalho limitam-se ao modelo determinado para a análise e seus dados de entrada. No entanto, a metodologia desenvolvida é uma operacionalização de prova conceitual e pode ser aplicada em outros municípios e morfologias urbanas.

\section{Referências}

ALRUBAIH, M. S. et al. Research and

Development on Aspects of Daylight

Fundamentals. Renewable and Sustainable

Energy Reviews, v. 21, p. 494-505, 2013.

ARAÚJO, I. Á. L. de; CABÚS, R. C. Influência da Luz Natural Refletida Pelo Entorno na Iluminação de Edifícios em Cânions Urbanos no Trópico

Úmido. In: ENCONTRO NACIONAL, 9.;

ENCONTRO LATINO AMERICANO DE

CONFORTO NO AMBIENTE CONSTRUÍDO,

5., Ouro Preto, 2007. Anais... Ouro Preto, 2007. 
ASSIS, E. S. A Abordagem do Clima Urbano e Aplicações no Planejamento da Cidade: reflexões sobre uma trajetória. In: ENCONTRO NACIONAL DE CONFORTO NO AMBIENTE CONSTRUÍDO, Maceió, 2005. Anais... Maceió, 2005.

\section{ASSOCIAÇÃO BRASILEIRA DE NORMAS} TÉCNICAS. NBR 15215-1: iluminação natural: parte 1: conceitos básicos e definições. Rio de Janeiro, 2005a.

\section{ASSOCIAÇÃO BRASILEIRA DE NORMAS} TÉCNICAS. NBR 15215-2: iluminação natural: parte 2: procedimentos de cálculo para a estimativa da disponibilidade de luz natural. Rio de Janeiro, $2005 b$.

\section{ASSOCIAÇÃO BRASILEIRA DE NORMAS} TÉCNICAS. NBR 15215-3: iluminação natural: parte 3: procedimento de cálculo para a determinação da iluminação natural em ambientes internos. Rio de Janeiro, 2005c.

\section{ASSOCIAÇÃO BRASILEIRA DE NORMAS TÉCNICAS. NBR 15575-1: Edificações habitacionais: desempenho: parte 1: requisitos gerais. Rio de Janeiro, 2013.}

BAKER, N.; FANCHIOTTI, A.; STEEMERS, K. Daylighting in Architecture: an European reference book. Bruxelas: James \& James, 1998.

CAPELUTO, I. G. The Impact of Urban Layout and External Obstructions on the Potencial Use of Daylighting. In: CONFERENCE ON PASSIVE AND LOW ENERGY ARCHITECTURE, 20., Santiago, 2003, Anais... Chile, 2003.

CINTRA, M. S. Arquitetura e Luz Natural: a influência da profundidade de ambientes em edificações residenciais. Brasília, 2011. Dissertação (Mestrado em Engenharia Civil) Programa de Pesquisa e Pós-Graduação da Faculdade de Arquitetura e Urbanismo, Universidade de Brasília, Brasília, 2011.

FONSECA, R. W.; FERNANDES, F. F. A.; PEREIRA, F. O. R. Zoneamento Bioclimático Referente à Iluminação Natural Para o Território Brasileiro. In ENCONTRO NACIONAL, 14.; ENCONTRO LATINO AMERICANO DE CONFORTO NO AMBIENTE CONSTRUÍDO, 10., Camboriú, 2017, Anais... Camboriú, 2017.

FROTA, A B. Geometria da Insolação. São Paulo: Geros, 2004.
GUEDES, A. F. Análise da Iluminação Natural a Partir do "Regulamento Técnico da Qualidade para Eficiência Energética de Edifícios Residenciais": simulação em edifícios multifamiliares de Belo Horizonte. Belo Horizonte, 2012. Dissertação (Mestrado em Engenharia Civil) - Programa de Pós-Graduação em Ambiente Construído e Patrimônio Sustentável, Universidade Federal de Minas Gerais, Belo Horizonte, 2012.

GUIDI, C. R. et al. Influência da Topografia na Admissão da Luz Natural em Edifícios Residenciais: estudo de caso em Belo Horizonte. In ENCONTRO NACIONAL, 14.; ENCONTRO LATINO AMERICANO DE CONFORTO NO AMBIENTE CONSTRUÍDO, 10., Camboriú, 2017. Anais... Camboriú, 2017.

INSTITUTO NACIONAL DE METROLOGIA, NORMALIZAÇÃO E QUALIDADE INDUSTRIAL. Portaria $\mathbf{n}^{\mathbf{0}} \mathbf{1 8}, 16$ de janeiro de 2012, que regulamento Técnico da Qualidade para o Nível de Eficiência Energética de Edificações Residenciais (RTQ-R). Rio de Janeiro, 2012. Disponível em:

$<$ http://www.inmetro.gov.br/legislacao/rtac/pdf/RT AC001788.pdf>. Acesso em: 4 ago. 2016.

\section{LABEEE, M. Arquivos Climáticos em Formato} TRY, SWERA, CSV e BIN. Disponível em: $<$ http://www.labeee.ufsc.br/downloads/arquivosclimaticos/formato-try-swera-csv-bin>. Acesso em: 4 nov. 2016.

LAMBERTS, R.; DUTRA, L.; PEREIRA, F. O. R. Eficiência Energética na arquitetura. 3. ed. Rio de Janeiro: Eletrobras; Procel; Procel Edifica, 2014.

LARANJA, A. C.; GAZZANEO, L. M. C.; CABÚS, R. C. Regulamentações Urbanas e Edilícias: considerações sob o aspecto da iluminação natural em ambientes interno. In: ENCONTRO NACIONAL DE CONFORTO NO AMBIENTE CONSTRUÍDO, Natal, 2009. Anais... Natal, 2009.

LEDER, M. S.; PEREIRA, F. O. R. Ocupação Urbana e Disponibilidade de Luz Natural. Revista Minerva: Pesquisa e Tecnologia, v. 5, n. 2, p. 129-138, 2008.

LEDER, M. S.; PEREIRA, F. O. R.; MORAES, L. N. Determinação Experimental de Coeficiente de Reflexão Médio Para Superfícies Verticais em Um Meio Urbano. In: ENCONTRO NACIONAL, 9.; ENCONTRO LATINO AMERICANO DE CONFORTO NO AMBIENTE CONSTRUÍDO, 5., Ouro Preto, 2007. Anais... Ouro Preto, 2007. 
MORAES, O. de; SCARAZZATO, P. S. Iluminação Natural no Meio Urbano: estudo de caso com o método dos indicadores de altura admissíveis aplicado a Campinas, SP. In: ENCONTRO NACIONAL DE CONFORTO NO AMBIENTE CONSTRUÍDO, Curitiba, 2003. Anais... Curitiba, 2003.

PEREIRA, R. C.; PEREIRA, F. O. R.; CLARO, A. Caracterização da Contribuição do Entorno na Avaliação da Iluminação Natural em Edificações. Ambiente Construído, Porto Alegre, v. 8, n. 4, p. 103-115, out./dez. 2008.

PREFEITURA MUNICIPAL DE BELO HORIZONTE. Lei $n^{\circ}$ 7.166, 27 de agosto de 1996, que estabelece normas e condições para parcelamento, ocupação e uso do solo urbano no município. Diário Oficial do Município, Belo Horizonte, 1996. Disponível em: $<$ http://cmbhsilinternet.cmbh.mg.gov.br:8080/silin ternet/consultaNormas/detalheNorma.do?id=2c907 f761753b10d01177939b4730059\&metodo=detalh ar\#>. Acesso em: 2 out. 2016.

\section{PREFEITURA MUNICIPAL DE BELO} HORIZONTE. Lei no 9.725, de 15 de julho de 2009, que institui o Código de Edificações do Município de Belo Horizonte e dá outras providências, Anexo III. Diário Oficial do Município, Belo Horizonte, 2009. Disponível em: $<$ https://leismunicipais.com.br/codigo-de-obrasbelo-horizonte-mg>. Acesso em: 11 out. 2016.

PREFEITURA MUNICIPAL DE BELO HORIZONTE. Mapa da Tipologia de Uso e Ocupação em Belo Horizonte 2011. Secretaria Municipal de Desenvolvimento. Belo Horizonte, 2011. Disponível em:

$<$ http://portalpbh.pbh.gov.br/pbh/ecp/comunidade. do?evento=portlet\&pIdPlc=ecpTaxonomiaMenuP ortal\&app=planejamentourbano\&lang=pt_br\&pg= 8843\&tax $=35739>$. Acesso em: 5 maio 2017.

\section{PREFEITURA MUNICIPAL DE BELO}

HORIZONTE. Mapa de Adensamento

Construtivo de Belo Horizonte - ano 2006. In: III CONFERÊNCIA MUNICIPAL DE POLÍTICA URBANA: estudo urbanos: transformações recentes na estrutura urbana. Núcleo de Planejamento Urbano da Secretaria Municipal de Políticas Urbanas. Belo Horizonte, 2007.

Disponível em:

$<$ http://www.pbh.gov.br/comunicacao/RELATORI OS/200905_estudos_urbanos_conferencia_abertur a_conferencia.pdf $>$. Acesso em: 15 out. 2016.
PREFEITURA MUNICIPAL DE BELO

HORIZONTE. Mapa de Declividade de Belo

Horizonte. Secretaria Municipal de

Desenvolvimento. Belo Horizonte, fev. 2013.

Disponível em:

$<$ http://portalpbh.pbh.gov.br/pbh/ecp/files.do?even to=download\&urlArqPlc=decliv_perc_a3.pdf $>$. Acesso em: 8 set. 2016.

\section{REINHART, C. F. Advanced Daylight}

Simulation Software: DAYSIM Versão 3.1, 2012. Disponível em: <http://daysim.ning.com/>. Acesso em: 11 out. 2016

REINHART, C. F. Tutorial on the Use of Daysim Simulations For Sustainable Design. Institute for Research in Construction, National Research Council Canada, Ottawa, ago. 2006.

ROBBINS, C. L. Daylighting: design and analysis. New York: Van Nostrand Reinhold, 1986.

SANTOS, I. G.; AUER, T.; SOUZA, R. V. G. Optimized Indoor Daylight For Tropical Dense Urban Environments. Ambiente Construído, Porto Alegre, v. 17, n. 3, p. 87-102, jul./set. 2017.

SCHELLER, C. et al. Análise de Arquivos Climáticos Para a Simulação do Desempenho Energético de Edificações. Engenharia Civil, Universidade Federal de Santa Catarina, Laboratório de Eficiência Energética em Edificações. 2015. Relatório técnico.

SOUZA, R. V. G. Iluminação Natural em Edificações: cálculo de iluminâncias interna: desenvolvimento de ferramenta simplificada. Florianópolis, 1997. Dissertação (Mestrado em Engenharia Civil) - Curso de Pós-Graduação em Engenharia Civil, Universidade Federal de Santa Catarina, Florianópolis, 1997.

\section{Agradecimentos}

As autoras agradecem à Coordenação de Aperfeiçoamento de Pessoal de Nível Superior (CAPES) e ao Conselho Nacional de Desenvolvimento Científico e Tecnológico (CNPq) pela concessão de bolsas de pesquisa. 


\section{Cláudia Rocha Guidi}

Departamento de Tecnologia do Design, da Arquitetura e do Urbanismo | Universidade Federal de Minas Gerais | Rua Paraíba, 697, Funcionários | Belo Horizonte - MG - Brasil | CEP 30130-141 | Tel.: (031) 98708-5126 | E-mail: claudiarguidi@gmail.com

\section{Karla Cristina de Freitas J orge Abrahão}

Departamento de Tecnologia do Design, da Arquitetura e do Urbanismo | Universidade Federal de Minas Gerais | Tel.: (031) 99617-6013 | E-mail: kjabrahao@hotmail.com

\section{Ana Carolina Oliveira Veloso}

Departamento de Tecnologia do Design, da Arquitetura e do Urbanismo | Universidade Federal de Minas Gerais | Tel.: (031) 98456-6902 | E-mail: acoveloso@gmail.com

\section{Roberta Vieira Gonçalves de Souza}

Departamento de Tecnologia do Design, da Arquitetura e do Urbanismo | Universidade Federal de Minas Gerais | Tel.: (031) 3409-8872 | E-mail: robertavgs2@gmail.com

\section{Revista Ambiente Construído}

Associação Nacional de Tecnologia do Ambiente Construído

Av. Osvaldo Aranha, 99 - 3o andar, Centro

Porto Alegre - RS - Brasil

$$
\text { CEP 90035-190 }
$$

Telefone: +55 (51) 3308-4084

Fax: +55 (51) 3308-4054

www. seer. ufrgs. br/ ambienteconstruido

E-mail: ambienteconstruido@ufrgs.br 